\title{
TOXIC AND CHEMOSTERRILIZING EFFECT OF SOME PLANT EXTRACTS ON THE COWPEA BEETLE Callosobruchus maculatus(F.) \\ Boraie, Doaa M. ${ }^{\star * \star}$; Hoda A. Ahmed* ; M. E. El-Naggar** and Hoda A. Salem* \\ * Mansoura University, Faculty of Science, Department of Zoology. \\ ** Agriculture Research Center, Ministry of Agriculture. \\ *** Plant Protection Research Institute, Agric. Res. Center.
}

\section{ABSTRACT}

Toxic and chemosterrilizing effect of fennel (Foeniclum vulgare) and cress Seeds (Eruca sativa) extracts in (petroleum ether, acetone and ethanol) and Jojoba oil on the adults of Cowpea beetles Callosobruchus maculatus(F.) were evaluated. Results showed a high mortality values with high concentrations of cress Seeds extracts and Jojoba oil while Fennel extracts exhibited low mortality with all used concentrations. Insect mortality increase with the increasing of concentration and exposure period. At high concentrations all tested extracts had a pronounced effect on female reproduction. The reproduction of C.maculatus female was completely inhibited by using high concentration of Jojoba oil or cress seeds extraction in petroleum ether.

\section{INTRODUCTION}

The cowpea beetle, Callosobruchus maculatus (F.) is a major pest of several legumes plants. It attacks stored cowpea and has a worldwide distribution. Severe losses due to this pest have been reported in several tropical and subtropical countries. The bioactivity of several plant extracts , natural dusts and plant oils as pest control agents against stored products pests was studied by many investigators (Jadhav and Jadhav, 1984; El sayed and Abdel-Rahik ,1984; Anduradha ,2002 ; Abdel- Latif, $2003 . . . . . . . . . e t c)$.

The present study aims to evaluate the toxic and chemosterrilizing effect of Jojoba oil as well as extractions of Fennel (Foeniclum vulgare) and Cress seeds (Eruca sativa) in (petroleum ether, acetone and ethanol) on Callosobruchus maculatus adults.

\section{MATERIALS AND METHODS}

\section{1- insect sources:}

To start a culture of cowpea beetle, Callosobruchus maculatus (F.), pairs of beetle adults (male and female) were reared in glass jars (each of approximately $500 \mathrm{ml}$ ) containing about $150 \mathrm{gm}$ of cowpea seeds. Each jar was covered with muslin cloths and fixed with rubber bands.

To have an initial population of C.maculatus adults homogenous in age, about 500 adults were introduced into jars for egg laying and then kept in an incubator at $28 \pm 2^{\circ} \mathrm{C}$ and $65 \pm 5 \%$ R.H. after two days, all insects were removed from the media and the jars were kept again at controlled conditions. 


\section{Boraie, Doaa M. et al.}

\section{2- plant extractions:}

to obtain the plant extracts, $250 \mathrm{gm}$ from every tested plants (Fennel, Foeniclum vulgare and Cress Seeds, Eruca sativa) were grounded in an electric mill into fine powder. The grounded plant material was soaked in the solvent in a large flask for $72 \mathrm{hrs}$. the flask was shacked for one hour in a shaker and its content was filtered. The solvent was evaporated at $50^{\circ} \mathrm{C}$ under reduced pressure using a rotary evaporator as described by $\mathrm{Su}$ (1985) . The extract in the form of a crude gum was weighted and dissolved by the same solvent to get $10 \%(\mathrm{w} / \mathrm{v})$ stock solution. Concentrations of $1,0.5,0.25$ and $0.125(\mathrm{w} / \mathrm{v})$ were prepared by diluting the stock solution in the solvent.

Commercial jojoba oil was tested at a concentration of $2,4.6$ and 8 $\mathrm{ml} / \mathrm{kg}$.

Fennel leaves, cress seeds and commercial Jojoba oil were obtained from herpshop.

\section{3-bioassay tests:}

to investigate the effect of plant extracts and Jojoba oil on cowpea beetle, ten grams of cowpea seeds were put into glass jars of $50 \mathrm{ml}$ mixed with plant extract or oil and left for extract dryness (24hrs) and oil absorption (28hrs). 20 adult insects $(0-24 \mathrm{hrs}$ old) were confined into the treated cowpea seeds. Jars were covered with muslin fixed with rubber bands and kept at $28 \pm 2{ }^{\circ} \mathrm{C}$ and $65 \pm 5 \%$ R.H. every treatment was replicated three times. A set of jars contained untreated seeds were used as check.

To evaluate the efficacy of the tested extracts on C.maculatus, the mortality percentages were estimated after $1,2,3,5$ and 7 days of exposure. Mortality percentages corrected using Abbot's formula (1925). The number of offspring (progeny) was also investigated after 30 days from treatment.

Reduction percentage in progeny of offspring calculated by the following equation (El-Lakwah et al. 1996)

$\%$ reduction $=\frac{\text { Offspring emerged in control }- \text { offspring emerged in treatment }}{\text { Offspring emerged in control }} * 100 \%$

\section{RESULTS AND DISCUSSION}

Table (1) indicated that the mortality rate increase with the increasing of oil conc. and exposure period. After 7 days from initial treatment, mortality values were $96.3,92.6,63$ and 48 at $8,6,4$ and $2(\mathrm{ml} / \mathrm{kg})$ respectively.

Jojoba oil had a pronounced effect on female reproduction especially by using high concentration.

Reduction in progeny ranged from $99.2-100 \%$ at all tested concentrations

The obtained results are in harmony with the results of Paranagama et al. (2002);; Abdel-Latif ,(2003); Yahaya, (2003) ; Priyani et al. (2003) ; ElKashlan (2004) and Alok et al. (2005) reported other plants oils against C.maculatus adults. 
1-Effects of Jojoba oil on C.maculatus adults:

Table (1):toxic and chesterrilizing effect of jojoba oil on adults of $C$. maculatus infesting cowpea seeds and (\%) reduction in F1progeny at $28 \pm 2^{\circ} \mathrm{C}$ and $65 \pm 5 \%$ R.H.

\begin{tabular}{|c|c|c|c|c|c|c|c|}
\hline $\begin{array}{l}\text { Conc. } \\
(\mathrm{ml} / \mathrm{kg})\end{array}$ & \multicolumn{5}{|c|}{ Adult mortality after indicated days } & \multirow{2}{*}{\begin{tabular}{|c}
$\mathbf{F 1}$ \\
progeny \\
after 22 \\
days
\end{tabular}} & \multirow{2}{*}{$\begin{array}{c}\% \\
\text { reductio } \\
n \text { in f1 } \\
\text { progeny }\end{array}$} \\
\hline & 1 & 2 & 3 & 5 & 7 & & \\
\hline 8 & $18.3 \pm 9.3$ & $38.3 \pm 20.5$ & $71.7 \pm 10.9$ & $96 \pm 3.3$ & $96.3 \pm 3.3$ & . & 100 \\
\hline 6 & $5 \pm 2.89$ & $26.7 \pm 4.4$ & $60 \pm 5$ & $87.7 \pm 6$ & $92.6 \pm 3.3$ & . & 100 \\
\hline 4 & . & $3.3 \pm 3.3$ & $16.7 \pm 11.6$ & $42 \pm 10.4$ & $63 \pm 10.9$ & $T$ & 99.6 \\
\hline 2 & . & . & $6.7 \pm 1.7$ & $19.3 \pm 4.4$ & $48 \pm 10$ & $r$ & 99.2 \\
\hline Check & & & & & & $r \leqslant A$ & \\
\hline
\end{tabular}

According to Abdel-Latif (2003) four plant oils; almond, colocynth, sesame and castor bean, mixed with cowpea or chickpea seeds exhibited high percentage of mortality against C.maculatus . Mortality of C.maculatus adults increased with the rise of oil concentration and exposure period. All oils at 4,6 and $8 \mathrm{ml} / \mathrm{kg}$ caused $100 \%$ kill after 5 days from treatment, except castor oil on chickpea seeds which gave 96.6 and $98.3 \%$ kill at 4 and $6 \mathrm{ml} /$ $\mathrm{kg}$, respectively. No adult emergence was observed on cowpea and chickpea seeds at thee rates, while at $2 \mathrm{ml} ; \mathrm{kg}$, a few number emerged.

2-Effects of plant extracts on C.maculatus adults:

Results concerning the toxic effect of fennel (Foeniclum vulgare) and cress seeds (Eruca sativa) extracts in petroleum ether, acetone and ethanol extracts on mortality and reduction in progeny of $C$. maculatus are given in Tables (2\&3). Mortality values increase with the increasing of concentration and exposure period especially with petroleum ether extracts. After 7 days from initial treatment, mortality values were $72,44.4,38.9$ with the highest concentration of fennel extracts in petroleum ether, acetone and ethanol respectively. In respect to cress seeds extracts ,the mortality percentage were 100,100,81.4with the highest concentration of cress seeds extracts in petroleum ether, acetone and ethanol respectively. In general, Cress seeds extracts were most effective than fennel extracts under study.

Reduction in progeny ranged from $80.2-100 \%, 62.5-94.4 \%$ and 10.9- $76.6 \%$ with fennel extracts in petroleum ether, acetone and ethanol at various concentrations respectively. With respect to cress seeds extraction in petroleum ether , acetone and ethanol ranged from $99.2-100 \%, 74.6-100 \%$ and $6.8-16 \%$ at $1.0 .5,0.25$ and $0.125 \%(\mathrm{w} / \mathrm{v})$ respectively.

The obtained results are in harmony with results of AbdEl-Aziz (2002) ; Al-Lawati et al. (2002) ; Sharma et al. (2003) ; Adedire and Akinneye (2004) ; Mollah et al. (2005) and Rotimi et al. (2006) .

AbdEI-Aziz (2002) Evaluated the toxic effects of petroleum ether extracts of cloves flowering buds (Syzygium aromaticum). Cinnamom, (Cinnamomum zeylanicum), Poinciana seeds (Delonix regia), radish seeds (Raphenus sativus) and mustard seeds (Brassica alba) against the adults of 
cowpea beetle Callosobruchus maculates alone and under controlled atmosphere (CA) of carbon dioxide at $25 \pm 5 \%$ concentration. Results showed high mortality values at various extract concentrations after 5 days from initial treatment. Insect mortality was positively correlated with the increase in exposure period and extract concentration. The extract of cloves was found to be more toxic than the other tested plant extracts.

Table (2): Toxic and chemosterrilizing effect of fennel (Foeniclum vulgare) extracts on $C$. maculatus adults infesting cowpea seeds and (\%) reduction in F1- progeny at $28 \pm 2^{\circ} \mathrm{C}$ and $65 \pm 5 \%$ R.H.

\begin{tabular}{|c|c|c|c|c|c|c|c|c|}
\hline \multirow{2}{*}{$\begin{array}{l}\text { Fennel } \\
\text { extraction } \\
\text { in: }\end{array}$} & \multirow[t]{2}{*}{$\begin{array}{l}\text { Conc. } \\
(w / v) \%\end{array}$} & \multicolumn{5}{|c|}{ Adult mortality after indicated days } & \multirow[t]{2}{*}{$\begin{array}{c}\text { No. of } \\
\text { offspring }\end{array}$} & \multirow{2}{*}{$\begin{array}{c}\% \\
\text { reduction } \\
\text { in } \mathrm{f1} \\
\text { progeny }\end{array}$} \\
\hline & & 1 & 2 & 3 & 5 & 7 & & \\
\hline \multirow{4}{*}{$\begin{array}{l}\text { petroleum } \\
\text { ether }\end{array}$} & 1 & $3.3 \pm 1.7$ & $13.3 \pm 1.7$ & $21.7 \pm 3.3$ & $49 \pm 6$ & $72 \pm 5.8$ & 0 & 100 \\
\hline & 0.5 & 0 & $3.3 \pm 1.7$ & $10 \pm 2.89$ & $14 \pm 9.3$ & $51.9 \pm 3.3$ & 0 & 10 \\
\hline & 0.025 & . & $1.7 \pm 1.7$ & \begin{tabular}{|l|}
6.671 .7 \\
\end{tabular} & $7 \pm 1.7$ & $37 \pm 6$ & 6 & 97.6 \\
\hline & 0.125 & $\cdot$ & 0 & 0 & $5 \pm 2.89$ & $16.7 \pm 2.89$ & 49 & 80.2 \\
\hline \multirow{4}{*}{ acetone } & 1 & $6.7 \pm 1.7$ & $13.3 \pm 1.7$ & $21.7 \pm 3.3$ & $28 \pm 6$ & $44.4 \pm 2.89$ & 14 & 94.4 \\
\hline & 0.5 & $3.3 \pm 1.7$ & $10 \pm 2.89$ & $18.3 \pm 1.7$ & $21 \pm 2.89$ & $25.9 \pm 1.7$ & 29 & 88.3 \\
\hline & 0.025 & $1.7 \pm 1.7$ & $5 \pm 2.89$ & $8.3 \pm 1.7$ & $8.7 \pm 1.7$ & $13 \pm 4.4$ & 78 & 68.5 \\
\hline & 0.125 & . & $1.7 \pm 1.7$ & $3.3 \pm 1.7$ & $7 \pm 4.4$ & $9.2 \pm 6$ & 93 & 62.5 \\
\hline \multirow{5}{*}{ Ethanol } & 1 & $\cdot$ & 0 & $13.3 \pm 1.7$ & $24.5 \pm 1.7$ & $38.9 \pm 2.89$ & 58 & 76.6 \\
\hline & 0.5 & $\cdot$ & $\cdot$ & $10 \pm 2.89$ & $14 \pm 3.3$ & $29.7 \pm 7.3$ & 167 & 32.7 \\
\hline & 0.025 & . & . & $6.7 \pm 1.7$ & $8.7 \pm 1.7$ & $14.8 \pm 1.7$ & 216 & 13 \\
\hline & 0.125 & $\cdot$ & $\cdot$ & 0 & $3.4 \pm 4.4$ & $7.4 \pm 1.7$ & 221 & 10.9 \\
\hline & check & & & & & & 248 & \\
\hline
\end{tabular}

Table (3): Toxic and chemosterrilizing effect of cress seeds (Eruca sativa) extracts on $C$. maculatus adults infesting cowpea seeds and (\%) reduction in F1- progeny at $28 \pm 2^{\circ} \mathrm{C}$ and $65 \pm 5 \%$ R.H.

\begin{tabular}{|c|c|c|c|c|c|c|c|c|}
\hline \multirow{2}{*}{$\begin{array}{l}\text { Cress } \\
\text { seeds } \\
\text { extraction } \\
\text { in: }\end{array}$} & \multirow[t]{2}{*}{$\begin{array}{l}\text { Conc. } \\
(w / v) \%\end{array}$} & \multicolumn{5}{|c|}{ Adult mortality after indicated days } & \multirow{2}{*}{$\begin{array}{c}\text { No. of } \\
\text { offsprin } \\
g\end{array}$} & \multirow{2}{*}{\begin{tabular}{|c|}
$\%$ \\
reductio \\
$\mathrm{n}$ in f1 \\
progeny
\end{tabular}} \\
\hline & & 1 & 2 & 3 & 5 & 7 & & \\
\hline \multirow{4}{*}{$\begin{array}{l}\text { Petroleum } \\
\text { ether }\end{array}$} & 1 & $96.7 \pm 3.3$ & $100 \pm 0$ & $100 \pm 0$ & $100 \pm 0$ & $100 \pm 0$ & 0 & 100 \\
\hline & 0.5 & $81.7 \pm 11.7$ & $88.3 \pm 9.3$ & $90 \pm 7.6$ & $93 \pm 4.4$ & $94.4 \pm 5$ & 0 & 100 \\
\hline & 0.025 & $68.3 \pm 7.3$ & $75 \pm 2.89$ & $76.7 \pm 3.3$ & $80.7 \pm 6$ & $79.7 \pm 3.3$ & 0 & 100 \\
\hline & 0.125 & $41.7 \pm 16$ & $45 \pm 17.6$ & $46.7 \pm 18.5$ & $56 \pm 9.3$ & $77.8 \pm 2.89$ & 2 & 99.2 \\
\hline \multirow{4}{*}{ acetone } & 1 & $100 \pm 0$ & $100 \pm 0$ & $100 \pm 0$ & $100 \pm 0$ & $100 \pm 0$ & 0 & 100 \\
\hline & 0.5 & $96.7 \pm 3.3$ & $100 \pm 0$ & $100 \pm 0$ & $100 \pm 0$ & $100 \pm 0$ & 1 & 99.6 \\
\hline & 0.025 & $43.3 \pm 14.8$ & $48.3 \pm 12$ & $55 \pm 7.4$ & $59.7 \pm 14.5$ & $66.7 \pm 11.6$ & 13 & 94.8 \\
\hline & 0.125 & $5 \pm 5$ & $16.7 \pm 6.8$ & $35 \pm 7.6$ & $54.4 \pm 10$ & $59.2 \pm 7.3$ & 63 & 74.6 \\
\hline \multirow{5}{*}{ Ethanol } & 1 & $3.3 \pm 3.3$ & $6.7 \pm 3.3$ & $16.7 \pm 4.4$ & $36.8 \pm 7.6$ & $81.4 \pm 4.4$ & 208 & 16 \\
\hline & 0.5 & $1.7 \pm 1.7$ & $3.3 \pm 1.7$ & $13.3 \pm 1.7$ & $24.5 \pm 4.4$ & $74 \pm 6.8$ & 220 & 11.3 \\
\hline & 0.025 & 0 & 0 & $8.3 \pm 1.7$ & $21 \pm 2.89$ & $68.5 \pm 1.7$ & 228 & 8 \\
\hline & 0.125 & 0 & 0 & $5 \pm 2.89$ & $14 \pm 3.3$ & $50 \pm 2.89$ & 231 & 6.8 \\
\hline & check & & & & & & 248 & \\
\hline
\end{tabular}




\section{REFERENCES}

Abbot, W.J. (1925). A method for computing the effectiveness of an insecticide .J.Econ.Entomol.,18:265-276 .

AbdEl-Aziz, A.E. (2002). Effectiveness of petroleum ether extract of some plants alone and under controlled atmospheres of carbon dioxide against the cowpea beetle. Annals of Agric. Sc., Moshtohor. 40(2): 1309-1319.

Abdel-Latif, A.M. (2003). Effect of some plants oils as protectants of stored legumes against cowpea beetle, Callosobruchus maculatus (F.) infestation. J. Agric., Res. \& Dev., 17(2).

Adedire, C.O. and Akinneye, J.O. (2004). Biological activity of tree marigold, Tithonia diversifolia, on cowpea seed bruchid, Callosobruchus maculatus (Coleoptera: Bruchidae). Annals-of-Applied-Biology, 144(2): 185-189.

Al-Lawati,H.T.; Azam, K.M. and Deadman, M.L. (2002). Potential of Omani flora as source of natural products for control of pulse beetle, Callosobruchus chinensis. Sultan-Qaboos-University-Journal-forScientific-Research -Agricultural-Sciences, 7: 1, 59-63; 10.

Alok-Krishna; Veena-Prajapati; Bhasney, S.; Tripathi, A.K. and Sushil-Kumar (2005). Potential toxicity of new genotypes of Tagetes (Asteraceae) species against stored grain insect pests. International-Journal-ofTropical-Insect-Science, 25(2): 122-128.

Anuradha,V.; Gowari-Neelima; Daniel,T. and Neelima,G. (2002). Effect of certain plant extracts on Callosobruchus maculatus as pest on stored pulses . Journal-of-Ecobiology, 14: 1, 67-71; 2.

El-Kashlan, I.H. (2004). Effects of some plant oils, Nemazal and Actellic on the protection of stored cowpeas Vigna sinensis (L.) against the infestation of cowpea weevil, Callosbruchus maculatus (F.). AlexandriaJournal-of-Agricultural-Research,49(1):37-47.

El-Lakwah, F.A.; Darwish, A.A. and Halawa, Z.A. (1996). Toxic effect of extracts and powders of some plants against the cowpea beetle (Callosobruchus maculatus, F.). Annals-of-Agricultural-Science,Moshtohor, 34(4): 1849-1859.

El-Sayed, F.M.A. and Abdel-Rahik, M. (1984). Citrus oils as protectants of cowpeas against infestation by Callosobruchus maculatus (F.) (Coleoptera: Bruchidae). Bulletin-of-the-Entomological-Society-ofEgypt,-Economic-Series, 14: 423-427.

Jadhav, K.B. and Jadhav, L.D. (1984). Use of some vegetable oils, plant extracts and synthetic products as protectants from pulse beetle, Callosobruchus maculatus Fabr. in stored gram. Journal-of-FoodScience-and-Technology,-India, 21(2): 110-113.

Mollah, J.U.; Islam, W. and Parween, S. (2005). Effectiveness of Polygonum hydropiper L. extracts against Callosobruchus maculatus F. infesting blackgram seeds. Journal-of-Agriculture-and-Rural-DevelopmentGazipur, 3(1/2): 147-150.

Paranagama, P.A.; Adhikari, A.A.C.K.; Abeywickrama, K.P. and Bandara, K.A.N.P. (2002). Toxicity and repellant activity of Cymbopogon citratus (D.C.) Stapf. and Murraya koenigii Sprang. against Callosobruchus maculatus (F.) (Coleoptera; Bruchidae). Tropical-AgriculturalResearch-and-Extension, 5(1/2): 22-28. 


\section{Boraie, Doaa M. et al.}

Priyani Paranagama*1, Chandika Adhikari1, Krishanthi Abeywickrama2 and Premarathne Bandara 3,(2003) . Deterrent effects of some Sri Lankan essential oils on oviposition and progeny production of the cowpea bruchid; Callosobruchus maculatus (F.) (Coleoptera; Bruchidae). University of Kelaniya, Kelaniya, Sri Lanka.3 Entomology Division, Horticultural Research and Development Institute, Gannoruwa, Sri Lanka,

Rotimi O. Akinkurolere 1 , Chris O. Adedire ${ }^{2}$ and Olusola O. Odeyemi² (2006). Laboratory evaluation of the toxic properties of forest anchomanes, Anchomanes difformis against pulse beetle Callosobruchus maculatus (Coleoptera: Bruchidae). Insect Science, 13(1):25.

Sharma,S.S.; Yadav, G.S. and Chhillar,B.S. (2003). Repellent activity of some plant extracts against Callosobruchus chinensis (L.) in chickpea grains. Annals-of-Biology, 19: 2, 217-218; 4 ref.

Su, H.C.F. (1985). Laboratory study on effects of Anetium graveoleus seeds on four species of stored product insects. J. Econ. Entomol. 78:451453.

Yahaya, M.M. (2003). Efficacy of selected seed oils against the longevity of cowpea weevil Callosobruchus maculatus (F.). Moor-Journal-ofAgricultural-Research, 4(1): 100-105.

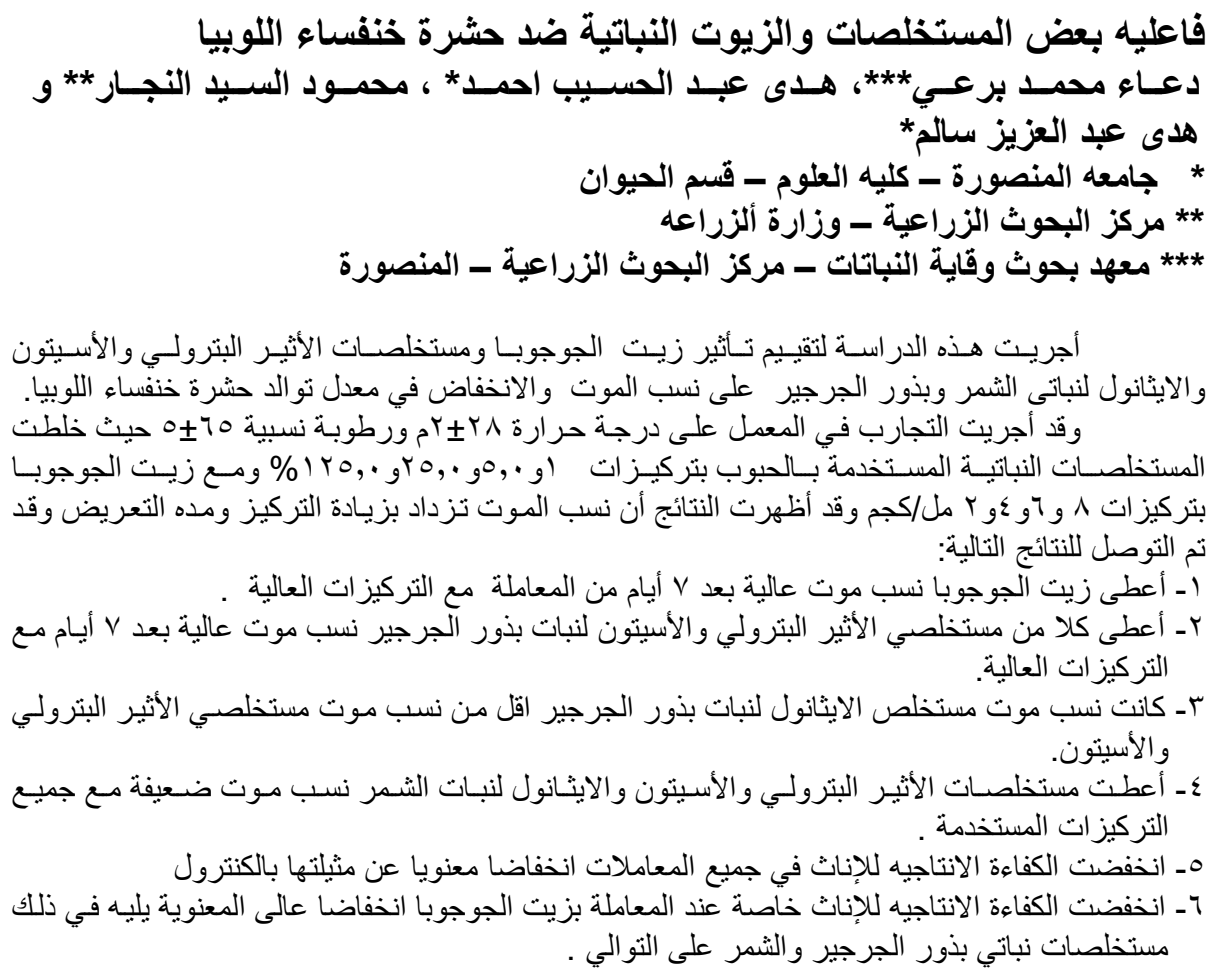

